\title{
CpG island methylation status in the EpCAM promoter region and gene expression
}

\author{
GUOLONG YU ${ }^{1,2}$, XIANGZHONG ZHANG ${ }^{3}$, HUAQIAO WANG ${ }^{1}$, \\ DERONG RUI ${ }^{4}$, AIHUA YIN ${ }^{1}$, GENG QIU ${ }^{4}$ and YUNSHAO HE ${ }^{4}$ \\ ${ }^{1}$ Department of Anatomy and Brain Research, Zhongshan School of Medicine, Sun Yat-sen \\ University, 510089; ${ }^{2}$ Guangdong Provincial Center for Disease Control and Prevention, \\ Guangdong Province 510300; ${ }^{3}$ The First Affiliated Hospital, Sun Yat-sen University, 510080; \\ ${ }^{4}$ Daan Gene Diagnosis Center of Sun Yat-sen University, Guangzhou 510089, P.R. China
}

Received March 3, 2008; Accepted June 5, 2008

DOI: 10.3892/or_00000110

\begin{abstract}
The epithelial cell adhesion molecule (EpCAM) gene has been found to be highly expressed in carcinomas of various origins; however, the molecular mechanisms underlying the transcriptional regulation of EpCAM remain poorly understood. The purpose of this experiment was to study the relationship between EpCAM gene overexpression and $\mathrm{CpG}$ island methylation status in the promoter region in cell cultures and normal colon epithelial and colorectal cancer tissues. Real-time quantitative PCR and bisulfite sequencing PCR were employed to detect EpCAM gene expression and to analyze the methylation status of the $\mathrm{CpG}$ islands. In addition, EpCAM gene expression and methylation status of $\mathrm{CpG}$ islands were studied in promoter methylation cell lines treated with a DNA methyltransferase inhibitor. It was found that most $\mathrm{CpG}$ dinucleotides were unmethylated in cell lines and cancer tissues where the EpCAM gene was highly expressed whereas most $\mathrm{CpG}$ dinucleotides were methylated in EpCAM gene unexpressed cell lines and normal colon tissues. When cells were treated with demethylating agent, $\mathrm{CpG}$ islands were demethylated, although EpCAM gene expression did not increase suggesting that unmethylation of the EpCAM promoter region was not responsible for EpCAM overexpression. The results of the study described herein suggest that unmethylation of the EpCAM promoter region was associated with EpCAM overexpression; however, it was not responsible for EpCAM overexpression by itself. Further research is required to determine which factors are responsible for EpCAM gene expression.
\end{abstract}

Correspondence to: Dr Yunshao He, Daan Gene Diagnosis Center of Sun Yat-sen University, Guangzhou 510089, P.R. China E-mail: alan7388@hotmail.com

Key words: epithelial cell adhesion molecule, promoter, methylation, 5-Aza-2'-deoxytidine, $\mathrm{CpG}$ island, bisulfate sequencing PCR

\section{Introduction}

The epithelial cell adhesion molecule (EpCAM) is encoded by the GA733-2 gene (1) and a $\mathrm{Ca}^{2+/-}$ independent homotypic cell-cell adhesion molecule with a size of $40 \mathrm{kDa}(2,3)$. EpCAM is often expressed on the base-lateral cell surface of human carcinoma and in most normal epithelial tissues as well (4). The gene's cDNA was independently cloned by a number of groups in the early 1990s (5-7) and was mapped to chromosome $2 q 21$ (8), although it was subsequently found that this gene was actually located on chromosome $4 \mathrm{q} 1$ (1).

Since EpCAM recognizes a tumor-associated antigen expressed by the majority of human epithelial neoplasias, it attracted major attention as a target for immunotherapy to combat human carcinomas $(9,10)$. Previously, the EpCAM gene was found to be highly expressed in carcinomas of various origins (11). It was also found that overexpression of EpCAM was related to the prognosis of these tumors (12-14). To elucidate the mechanisms that underlie the abnormal expression of the EpCAM gene in cancer cells, Gires et al and McLaughlin et al both studied the EpCAM gene promoter function. These groups found that the EpCAM gene was primarily controlled by regulatory sequences located 570 or 687 bp upstream of the 5'extreme of this gene $(15,16)$.

Altered DNA methylation at $\mathrm{CpG}$ dinucleotides in the promoter region has recently been recognized as an important mechanism for the regulation of gene expression in human cancers $(17,18)$. Hypomethylation of $\mathrm{CpG}$ dinucleotides were found in a number of genes involved with gene overexpression in cancers (19-23), while hypermethylation of the CpG island of the promoter region deregulates gene expression $(24,26)$. As a basis for the present study, the sequences of the EpCAM gene promoter were analyzed and found one $\mathrm{CpG}$ island located in the -366 to +612 bp region (http://genome.ucsc.edu) (position: chr2: 47449783-47450760, band: 2p21, genomic size: $978 \mathrm{CpG}$, count: 117, percentage $\mathrm{CpG}: 23.9 \%$, rate of observed to expected $\mathrm{CpG}: 0.88$ ). Information pertaining to whether $\mathrm{CpG}$ island methylation status correlated with gene expression and reports describing the relationship between the EpCAM gene promoter methylation status and gene expression were scant. Therefore, the purpose of this present investigation 
was to study the relationship between EpCAM gene overexpression and $\mathrm{CpG}$ island methylation status in the EpCAM promoter.

\section{Materials and methods}

Cell lines and culture conditions. The chosen cell lines were from different tissue and organ origin including: colon cancer cell lines, breast cancer cell lines, prostate cancer cell lines, liver cancer tissues and haematological tumor cell lines. The cell lines: HR-8348, HCT-8 and PC-3 were obtained from the Institute of Biochemistry and Cell Biology of Shanghai, P.R. China. The others were from our laboratory. Growth conditions of cell lines were as follows: Liver cancer cell lines (BEL-7407, BEL-7404, HepG2), colon cancer cell lines (HR-8348, HCT-8, LoVo), haematological tumor cell lines (Jurket, U937, J-111, HL-60, k562) and the breast cancer cell line (MCF-7) were grown in RPMI-1640 with 10-15\% fetal calf serum (FCS) in 5\% $\mathrm{CO}_{2}$ humidified atmosphere; Caco-2 (colon cancer cell line) was grown in Dulbecco's Modified Eagle's Medium (DMEM) with $10-15 \%$ FCS in $5 \% \mathrm{CO}_{2}$ humidified atmosphere; prostate cell lines (PC-3, LANcap) were grown in $\mathrm{F} 12$ with $10-15 \%$ FCS in $5 \% \mathrm{CO}_{2}$ humidified atmosphere.

Tissue specimens. Colon cancer and normal tissue samples were obtained from 16 colon cancer patients undergoing surgical therapy for the treatment of colon cancer at the Sun Yat-sen University Cancer Center. All tissue specimens were evaluated immediately at the time of excision by a surgical pathologist at the time of acquisition. Each colon cancer and normal tissue sample was divided into two parts. One part of the tissues was used to detect the EpCAM gene expression and the $\mathrm{CpG}$ island methylated status in promoter by real-timeqPCR and bisulfate sequencing PCR (BSP), while the other part was sent for routine pathology analysis. Normal colon tissue samples were obtained from the above-mentioned patients at least $3 \mathrm{~cm}$ away from malignant tissue sections.

Total RNA and DNA isolation. Total cellar RNA and genomic DNA was isolated from all cell lines and normal tissues and cancer tissues using an RNA and DNA extraction kit (Qiagen RNA/DNA kit, Germany) according to the manufacturer's instructions. RNA and DNA were quantified by UV spectrophotometer (Shimadzu, Japan) and stored at $-70^{\circ} \mathrm{C}$ until time of analysis.

Primer and probe design. Primers and probes for analyzing the EpCAM gene and $B$-actin were designed by Pekin-Elmer Primer Express software. The primers were designed to be intron-spanning to preclude amplification of genomic DNA. The primer and probe sequences were as follows: forward primer of EpCAM, 5'-ATC GTC AAT GCC AGT GTA CTT CA-3', reverse primer 5'-TTT GCT CTT CTC CCA AGT TTT GAG-3', Taq Mam probe FAM 5'-TTG CTC AAA GCT GGC TGC CAA ATG TTT-3 TAMRA); ß-actin, forward primer 5'-GCT CAC CAT GGA TGA TGA TAT C-3' reverse primer 5'-GCC AGA TTT TCT CCA TGT CG TC-3' Taq Mam probe FAM-5'-CAA CGG CTC CGG CAT GTG C-3'-TAMRA.
Quantified EpCAM gene expression in cell lines and tissues. Reverse transcription (RT) was performed using Wizard First-Strand synthesis kit (Promega Corporation, WI, USA) according to the manufacturer's instructions. Briefly, $1 \mu \mathrm{g}$ total RNA was reverse transcribed into cDNA in a total reaction volume of $25 \mu \mathrm{l}$, which contained $1 \mu \mathrm{M}$ of random primer, 200 units of MMLV reverse transcriptase, 1X Buffer and $200 \mu \mathrm{M}$ dNTPs. The mixture was incubated at $42^{\circ} \mathrm{C}$ for $1 \mathrm{~h}$, followed by $94^{\circ} \mathrm{C}$ for $10 \mathrm{~min}$ to inactive the reverse transcriptase. EpCAM mRNA levels were quantified by using ABI PRISM 7000 Sequence Detection System (PE Company, USA). The real-time-qPCR was carried out in a $50 \mu 1$ reaction volume containing $1 \mathrm{X}$ Buffer, $200 \mu \mathrm{M}$ dNTP, $200 \mathrm{nM}$ of both forward and reverse primers, $120 \mu \mathrm{M}$ Taq Mam probe, $5 \mu 1$ of cDNA template and 2.5 units Taq polymerase. The reaction was initially denatured at $94^{\circ} \mathrm{C}$ for $3 \mathrm{~min}$, then cycled 40 times at $94^{\circ} \mathrm{C}$ for $30 \mathrm{sec}$ and $55^{\circ} \mathrm{C}$ for $1 \mathrm{~min}$. $\beta$-actin was used as an internal control gene.

Data analysis. The real-time-qPCR results were analyzed by using Q-Gene software (27) and SPSS 10.0. Q-Gene software expressed data as mean normalized expression (MNE). MNE is directly proportional to the amount of RNA of the target gene (EpCAM) relative to the amount of RNA of the reference gene ( $($-actin). The standard error (SE) was calculated by Q-Gene software using the differential equation of Gauss.

Analyzing the methylation status in tumor cell lines and tissues

Bisulphite conversion reaction. Tissue DNA ( $3 \mu \mathrm{g})$ was denatured by adding freshly prepared $\mathrm{NaOH}$ to a final concentration of $0.3 \mathrm{M}$ in a reaction volume of $50 \mu 1$ and incubating for $15 \mathrm{~min}$ at $37^{\circ} \mathrm{C}$. To this, $30 \mu \mathrm{l}$ of $10 \mathrm{mM}$ hydroquinone (Sigma, MO, USA) and $520 \mu 1$ of $3 \mathrm{M}$ sodium bisulfite (Sigma) at pH 5.0 were added and mixed. The samples were incubated under mineral oil at $55^{\circ} \mathrm{C}$ for $16 \mathrm{~h}$. Modified DNA was purified using the Wizard DNA purification resin according to the manufacturer's instructions (Promega Corporation) and eluted in $50 \mu 1$ of water. Modification was completed by adding $\mathrm{NaOH}$ (to a final concentration of $0.3 \mathrm{M}$ ), incubated for $10 \mathrm{~min}$ at $37^{\circ} \mathrm{C}$, followed by ethanol precipitation. DNA was resuspended in $40 \mu 1$ of water and was either used immediately or stored at $-70^{\circ} \mathrm{C}$ until time of analysis.

PCR amplification and cloning sequencing. Six primers for EpCAM promoter region (Table I) were designed using oligo 6.0 and included the -499 to +612 regions. PCR was performed in a $50 \mu 1$ reaction volume that contained $1 \mathrm{X}$ Buffer, $200 \mu \mathrm{M}$ dNTPs, $200 \mathrm{nM}$ of both forward and reverse primers, $4 \mu 1$ bisulphite-treated genomic DNA template and 2.5 units Taq polymerase. The PCR products were ligated into the PMD18Tvector (Takara, Dalian, P.R. China) and transformed into competent $E$. coli (DH5a) according to manufacturer's instructions (Takara). Ten clones from each sample were sequenced by Bioasia Company, Shanghai.

Treatment with 5-Aza-2'-deoxytidine and EpCAM gene expression detection. In order to study the relationship between gene overexpression and $\mathrm{CpG}$ island methylation 
Table I. Primer sequences, position, product size and corresponding amplification PCR condition.

\begin{tabular}{|c|c|c|c|}
\hline Primer sequence $\left(5^{\prime}-3^{\prime}\right)$ & Position & Size & PCR condition \\
\hline 1F5'-GTTAAAAGGAAGTTTTAGTATAGAATT-3' & (499- to -259) & $240 \mathrm{bp}$ & $94^{\circ} \mathrm{C} 30 \mathrm{sec}, 52^{\circ} \mathrm{C} 35 \mathrm{sec}$ \\
\hline 1R5'-GAAACTACTCACCTCTAAC-3 & & & $72^{\circ} \mathrm{C} 40 \mathrm{sec}, 40$ cycles \\
\hline 2F5'-GTTAGAGGTGAGTAGTTT-3' & $(-277-$ to +82$)$ & $359 \mathrm{bp}$ & $94^{\circ} \mathrm{C} 30 \mathrm{sec}, 53^{\circ} \mathrm{C} 45 \mathrm{sec}$, \\
\hline 2R5'-CCTCACCTTCCTAAACTAC-3' & & & $72^{\circ} \mathrm{C} 50 \mathrm{sec}, 40$ cycles \\
\hline 3F5'-GTAGTTTAGGAAGGTGAGG-3' & $(+64-$ to +180$)$ & $116 \mathrm{bp}$ & $94^{\circ} \mathrm{C} 30 \mathrm{sec}, 56^{\circ} \mathrm{C} 25 \mathrm{sec}$ \\
\hline 3R5'-TCTTAATCCCCTCCCTATTATACC-3' & & & $72^{\circ} \mathrm{C} 25 \mathrm{sec}, 35$ cycles \\
\hline 4F5'-TATAATAGGGAGGGGATTAAGAGGT-3' & $(+159-$ to +324$)$ & $165 \mathrm{bp}$ & $94^{\circ} \mathrm{C} 30 \mathrm{sec}, 58^{\circ} \mathrm{C} 30 \mathrm{sec}$ \\
\hline 4R5'-GCCCAAAACCATTTCCCTACCAAAA-3 & & & $72^{\circ} \mathrm{C} 30 \mathrm{sec}, 35$ cycles \\
\hline 5F5'-TTTTGGTAGGGAAATGGTTTTGGGC-3' & $(+300-$ to +449$)$ & $149 \mathrm{bp}$ & $94^{\circ} \mathrm{C} 30 \mathrm{sec}, 58^{\circ} \mathrm{C} 30 \mathrm{sec}$ \\
\hline 5R5'-CTATTTTAAAACCCCAAATCCACCC-3' & & & $72^{\circ} \mathrm{C} 30 \mathrm{sec}, 35$ cycles \\
\hline 6F5'-GGGTGGATTTGGGGTTTTAAAATAG-3' & $(+425-$ to +668$)$ & $243 \mathrm{bp}$ & $94^{\circ} \mathrm{C} 30 \mathrm{sec}, 56^{\circ} \mathrm{C} 45 \mathrm{sec}$ \\
\hline 6R5'-ССТАCАATAААССТААСАТТАСТСАТАТА-3' & & & $72^{\circ} \mathrm{C} 40 \mathrm{sec}, 35$ cycles \\
\hline
\end{tabular}

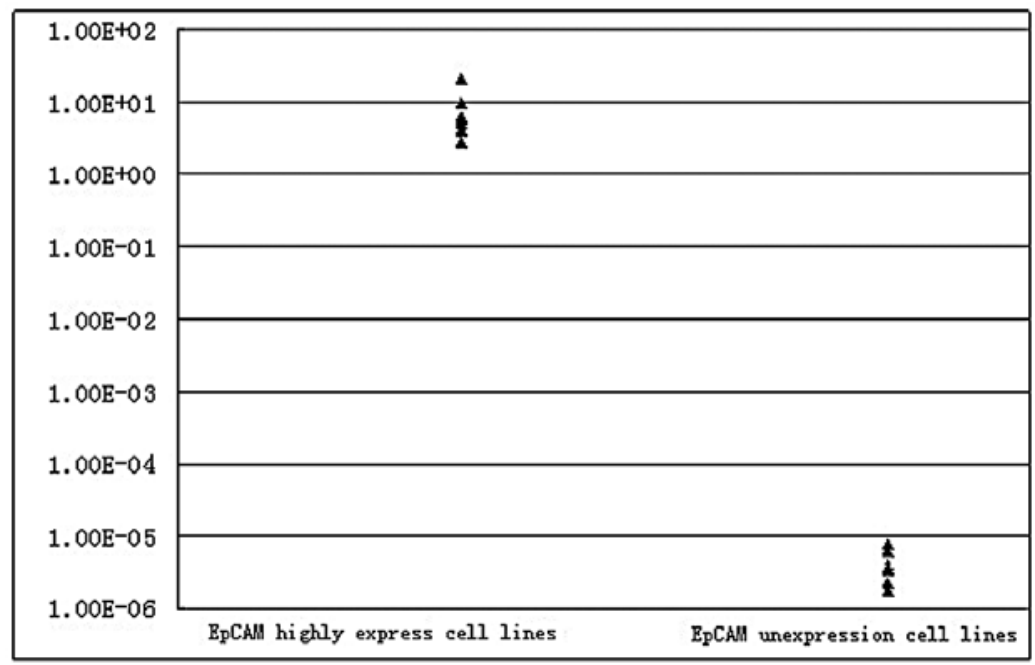

Figure 1. Real-time-qPCR analysis of EpCAM gene expression in various cell lines. EpCAM was highly expressed in colon (HR-8348, HCT-8, LoVo, Caco-2), prostate (PC-3, LANcap) and breast (MCF-7) cancer cell lines. In contrast, EpCAM was unexpressed in the haematological tumor cell lines (Jurket, U937, J-111, HL-60 and k562) and liver tumor cell lines (BEL-7407, BEL-7404 and HepG2). Data were expressed as MNE, which was directly proportional to the relative amount of mRNA in the cell lines. The MNE of each sample was determined from triplicate reactions using the Q-Gene software and SPSS10.0 (P<0.01).

status in the EpCAM promoter region, $\mathrm{CpG}$ island methylated cell line K562 and HepG2 were treated with 5-Aza-2'deoxytidine (Sigma). These cell lines were seeded at a density of $3 \times 10^{5}$ cells $/ 100 \mathrm{~mm}^{2}$ dish and allowed to settle over 24 h. 5-Aza-2'-deoxytidine was then added to the medium at a final concentration of $5 \mu \mathrm{M}$. Media were changed every $24 \mathrm{~h}$ with freshly prepared medium containing 5-Aza-2'deoxytidine. After $96 \mathrm{~h}$, cells were harvested and subjected to RNA and DNA extraction to detect EpCAM gene expression and promoter methylation status by real-time-qPCR and BSP.

Immunohistochemistry. A portion of 5-Aza-2'-deoxytidinetreated cells were analyzed by immunohistochemistry staining using the Elivision ${ }^{\mathrm{TM}}$ plus kit (Maixin Biological, Fuzhou, P.R. China) according to manufacturer's instructions. The reaction products were visualized with diaminobenzidine
(DAB) and slides were counterstained with hematoxylin, dehydrated and evaluated by light microscopy. Phosphatebuffered saline (PBS) solution was used instead of the primary antibody for negative controls.

\section{Results}

EpCAM expression in tumor cell lines. Real-time-qPCR analysis revealed that EpCAM was highly expressed in colon (HR-8348, HCT-8, LoVo, Caco-2), prostate (PC-3, LANcap), and breast (MCF-7) tumor cell lines. In contrast, EpCAM was expressed at very low to almost negligible levels in liver tumor cell lines (BEL-7407, BEL-7404 and HepG2) and haematological tumor (Jurket, U937, J-111, HL-60, k562) cell lines (Fig. 1). In cell lines with a high expression of EpCAM, the mean normalized expression (MNE) ranged between 

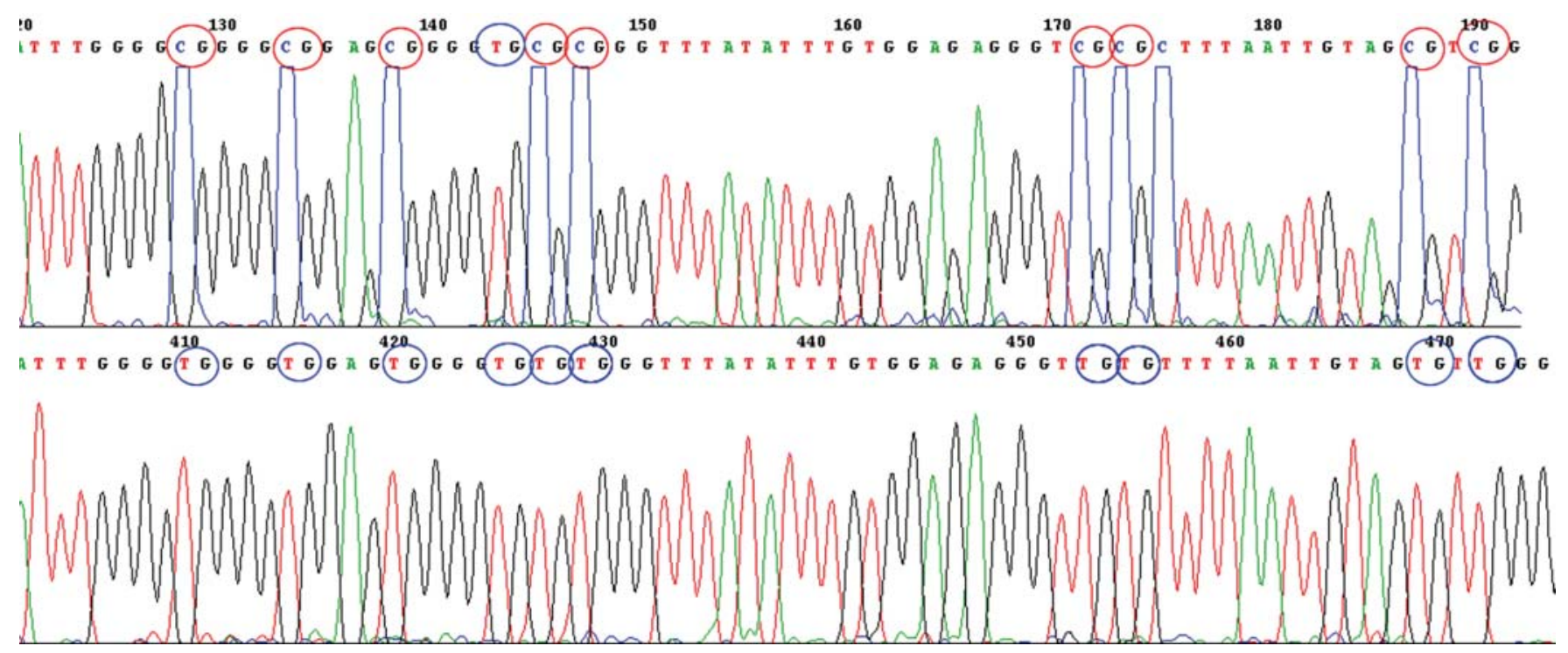

Figure 2. This figure was part of sequencing results from -417 to -354 region in EpCAM gene promoter region in the K562 (top) and PC-3 cell line (bottom). Methylated $\mathrm{CpG}$ dinucleotides appeared as CG, while unmethylated $\mathrm{CpG}$ dinucleotides appeared as TG. CpG dinucleotides were unmethylated and appeared as TG in the 4th $\mathrm{CpG}$ from left in this figure in the K562 cell line (top).

$2.14 \mathrm{E}+01$ and $2.82 \mathrm{E}+00$ [mean $=7.78 \mathrm{E}+00$; standard error $(\mathrm{SE})=6.36 \mathrm{E}+00]$ whereas in EpCAM unexpressed cell lines, $\mathrm{MNE}$ ranged between 7.56E-06 and 2.19E-06 (mean = 4.48E-06; SE $=2.04 \mathrm{E}-06$ ). These results indicated that EpCAM expression was different in the cell lines which come from different origin $(\mathrm{P}<0.01)$.

CpG island methylation status of the EPCAM gene promoter in tumor cell lines. Through clone sequencing, it was found that most of the $\mathrm{CpG}$ dinucleotides in the EpCAM promoter were unmethylated in cell lines of HR-8348, HCT-8, LoVo, Caco-2, MCF-7, PC-3 and LANcap that highly expressed in the EpCAM gene. In contrast, most of the $\mathrm{CpG}$ dinucleotides were methylated in cell lines of BEL-7407, BEL-7404, HepG2, Junket, U937, J-111, HL-60 and K562 EpCAM gene.

The promoter methylation region was divided in two parts. The first part was from -437 to -344 , and it included the Sp1 site (GGGGmCGGGG), while the second part was from -248 to +612 and included exon 1 and part of intron 1 . From -344 to -248 regions, around the Ap1 site, the $\mathrm{CpG}$ dinucleotides were unmethylated in all cell lines. Parts of the sequencing (-417 to -354$)$ results are shown in Fig. 2 and total methylation pattern of all cell lines is shown in Fig. 3A.

In liver and haematological tumor cell lines, the EpCAM gene was expressed at the same level; however, the $\mathrm{CpG}$ dinucleotide methylation status was found to be different. In liver cancer cell lines, $\mathrm{CpG}$ island methylation status was $\sim 50 \%$ of the $\mathrm{CpG}$ island methylation identified in the haematological cell line EpCAM gene promoter region (Fig. 3A).

EpCAM gene expression and CpGs methylation status in colon tissue samples. The EpCAM gene expression was different in normal colon tissues compared to colon cancer tissues. In the normal colon tissues, the MNE ranged between 4.58E-02 and 4.71E-03 (mean $=1.58 \mathrm{E}-02 ; \mathrm{SE}=1.29 \mathrm{E}-02)$.
In the colon cancer tissues, the MNE ranged between $2.95 \mathrm{E}+01$ and 3.80E+00 (mean $=4.48 \mathrm{E}-06 ;$ SE $=2.04 \mathrm{E}-06)$. These results indicate that the expression level of EpCAM was $\sim 1000$-fold higher in colon cancers than normal colon tissues $(\mathrm{P}<0.01)$. Routine pathology analysis diagnosed 11 colon cancer tissue samples were highly differentiated adenocarcinoma. The remaining 5 samples were poorly differentiated adenocinoma. The EpCAM expression was about the same level between these two groups $(\mathrm{P}>0.05)$.

Through bisulfite sequencing PCR, we found that the CpGs methylation status in the EpCAM gene promoter region was also different in normal colon tissues compared to colon cancer tissue. In colon cancer tissues, most $\mathrm{CpGs}$ were unmethylated, but in normal colon tissues, only $\sim 50 \%$ of the CpGs were unmethylated. The methylation status patterns were similar in all patients and a representative pattern is shown in Fig. 3B.

EpCAM gene expression after demethylation. After treatment with 5-Aza-2'-deoxytidine for $96 \mathrm{~h}$, most of the methylated CpGs were converted into unmethylated CpGs in the EpCAM gene promoter region in the HepG2 and K562 cell lines. The methylation statuses of all $\mathrm{CpG}$ dinucleotides are shown in Fig. 3C. Real-time-qPCR and immunohistochemistry were used to detect if the EpCAM gene could re-express after methylated $\mathrm{CpG}$ dinucleotides were converted to unmethylated status by 5-Aza-2'-deoxytidine in these two cell lines (Fig. 4).

Results revealed that in K562 cell lines, the MNE was $1.72 \mathrm{E}-06$ compared to $1.79 \mathrm{E}-06$ in the control cells. In HepG2 cell lines, the MNE was 2.32E-07 and the control was 2.53E-06. Thus, the EpCAM gene expression did not exhibit any remarkable changes after methylated $\mathrm{CpGs}$ were converted to unmethylated CpGs. The results from immunohistochemistry straining also demonstrated that the EpCAM gene did not re-express in HepG2 and k562 cell lines after the methylated $\mathrm{CpGs}$ converted to unmethylated $\mathrm{CpGs}$ by 5-Aza2'-deoxytidine (Fig. 5). 


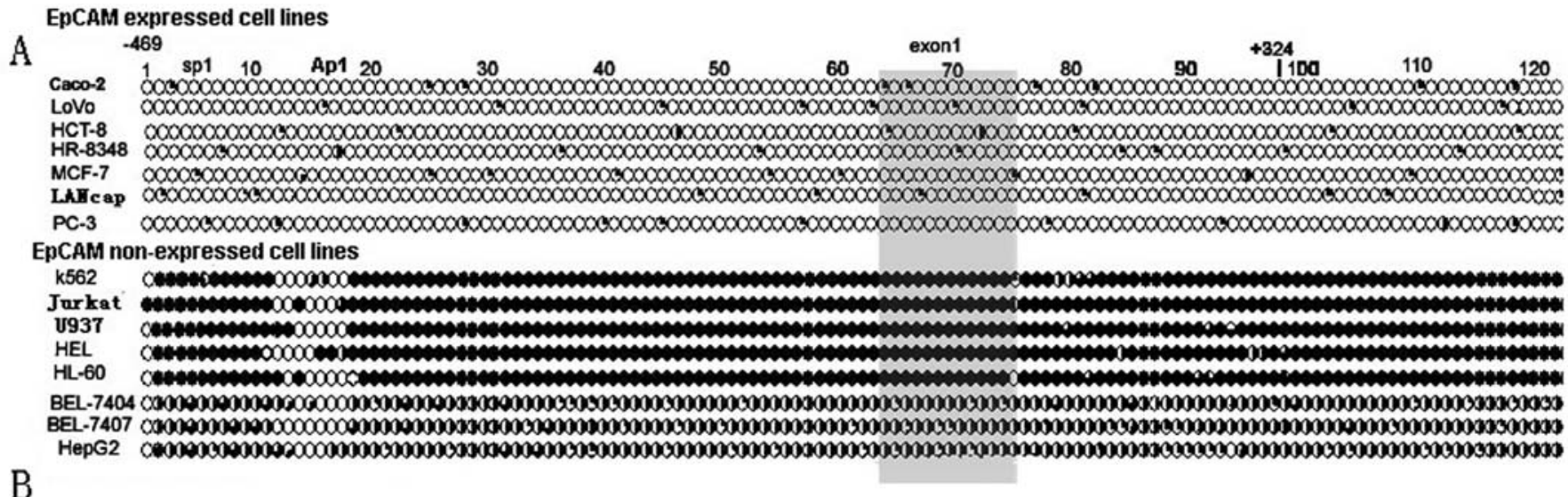

normal colon tissues

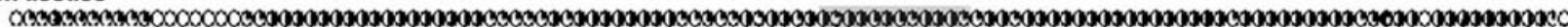

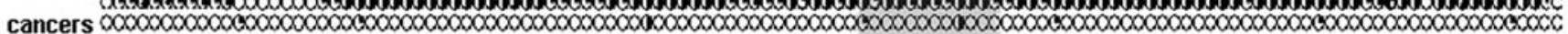

Cthe methylation status after treated with 5-AZA-dC.

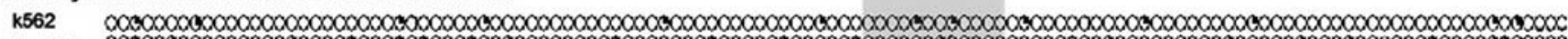

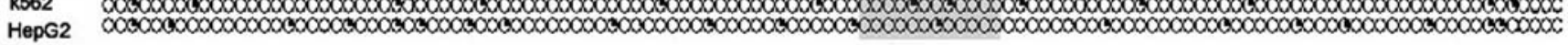

$00 \%-30 \%+50 \% 80 \% \cdot 100 \%$

Figure 3. Map and methylation status of the CpG islands in the promoter region of the EpCAM gene (-499- to +612). (A) CpGs methylation status in EpCAM highly expressed cell lines most CpGs in the promoter region were unmethylated. In contrast, most CpGs throughout the promoter region were methylated in the liver and haematological tumor cell lines, which did not express EpCAM. The patterns of methylation were divided into two parts in EpCAM promoter. (B) CpG dinucleotides methylation status in the normal colon tissue and colon cancer tissue. Most CpG dinucleotides were methylated in normal tissue but unmethylated in colon cancer tissues. (C) After treated with 5-Aza-2'-deoxytidine, the CpG methylation status in K562 and HepG2 cell lines in EpCAM gene promoter. Ten clones from each sample were sequenced by Bioasia Company, Shanghai. The methylation of each CpG site is shown by a circle and numbered relative to ATG site. Open circles represent unmethylated cytosines, black circles represent methylation and half-black circles represent sites with heterogeneous methylation of $\sim 50 \%$. Quarter black circles represent sites with heterogeneous methylation of $\sim 30 \%$.

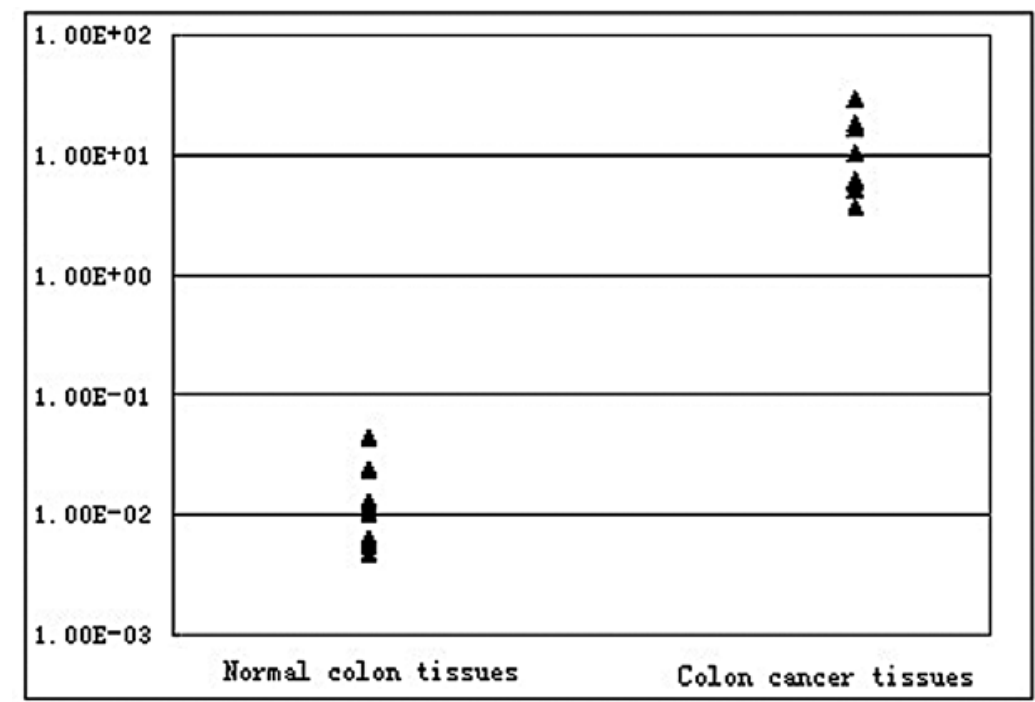

Figure 4. Reat-time qPCR analysis of normal colon tissue and colon cancer tissue samples. Data are expressed as MNE which is directly proportional to the relative amount of mRNA in a given tissue. The MNE of each samples was determined from triplicate reactions using the Q-Gene software and SPSS10.0 $(\mathrm{P}<0.01)$

\section{Discussion}

The putative EpCAM promoter contained consensus-binding sites for the $\mathrm{Sp} 1$ and Ap1 transcription factors, but no TATA or CAAT boxes were found (1) and the Sp1 site protected the promoter from methylation $(28,29)$. The $\mathrm{CpG}$ islands provided in human genome data (http://genome.ucsc.edu) did not include either the $\mathrm{Sp} 1$ or Ap1 sites. In order to determine the methylation status of Sp1 and Ap1, we chose -499-+612 position in the promoter region and real-time qPCR and BSP were employed to study the relationship between EpCAM gene expression and $\mathrm{CpG}$ island methylation status.

In this study, it was found that the EpCAM gene was overexpressed in colon, breast and prostate cancer cell lines, but not in liver or haematological tumor cell lines. The $\mathrm{CpG}$ island methylation status was also different in each of these cell lines which have different origins. In EpCAM highly expressed cell lines, the $\mathrm{CpG}$ islands were unmethylated, which was in 


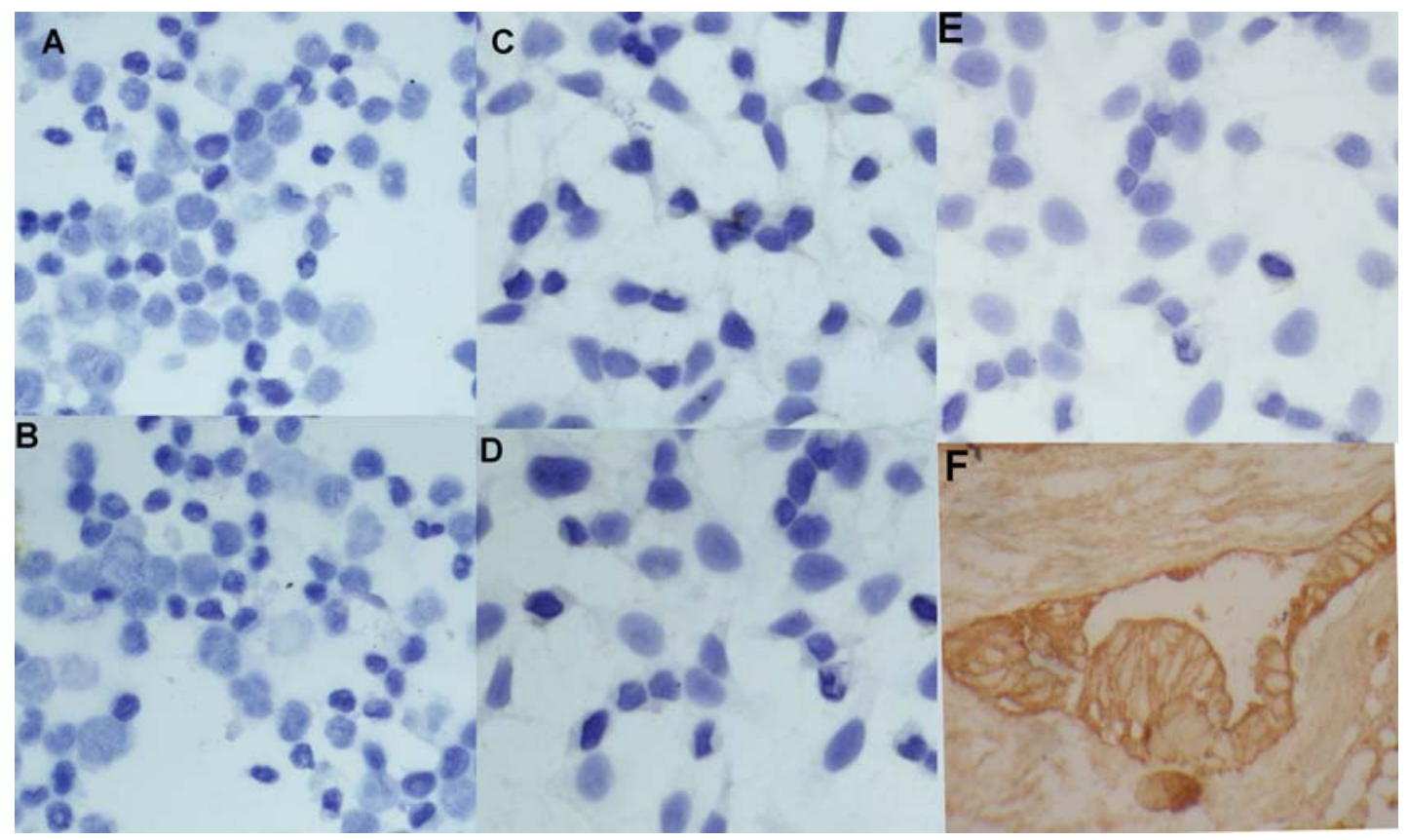

Figure 5. Immunohistochemistry was used to detect the EpCAM gene expression. (A) After treated with 5-Aza-2'-deoxytidine, the K562 cell line was not EpCAM gene expression did not change obviously after methylated CpGs converted to unmethylated in the K562 cell line. (B) Control K562 cell line. (C) After treated with 5-Aza-2'-deoxytidine, EpCAM gene expression did not change obviously after methylated CpGs converted to unmethylated in the HepG2 cell line. (D) Control HepG2 cell line. (E) K562 negative control. (F) Colon cancer tissue as positive control.

contrast to the EpCAM unexpressed cell lines where the $\mathrm{CpG}$ island was methylated. In normal colon tissues, the EpCAM gene was expressed less than in colon cancer tissues. Further, the $\mathrm{CpG}$ islands were unmethylated in colon cancer tissues, but approximately half of the $\mathrm{CpG}$ islands in the promoter region were methylated in normal colon tissue. Based on these results, it appears that EpCAM gene expression was associated with $\mathrm{CpG}$ island methylation and methylation level was related to EpCAM gene expression.

To determine if $\mathrm{CpG}$ island unmethylation was driving gene overexpression, K562 and HepG2 were selected as targeted cell lines because their origin and $\mathrm{CpG}$ dinucleotide methylation status were different. It was suggested that if the EpCAM gene was re-expressed after $\mathrm{CpG}$ dinucleotides were demethylated, then it may be reasonable to conclude that some methylation sites may be critical in EpCAM gene expression. This supposition was presented based on the fact that $\mathrm{CpG}$ dinucleotide methylation status affects EpCAM gene expression. Therefore, if the EpCAM gene did not re-express after demethylation, then obviously methylation was not responsible for EpCAM gene overexpression. In this study, after the $\mathrm{CpG}$ islands were demethylated, EpCAM gene expression level did not increase in either cell line. Furthermore, the immunohistochemistry analysis did not reveal any EpCAM gene expression in either of the two cell lines. These findings indicate that even if all $\mathrm{CpG}$ dinucleotides were demethylated in EpCAM gene promoter region, EpCAM gene would not re-express. Although $\mathrm{CpG}$ island demethylation appeared to be associated with EpCAM gene overexpression, this demethylation was actually not responsible for the observed overexpression. That is to say that there may be other factors that regulate EpCAM gene expression besides promoter demethylation.
A recent study implicated promoter methylation in the regulation of EpCAM expression in breast cancer cell lines and tissues (30). This group found that promoter methylation did not appear to be a crucial mechanism for regulation of gene expression. In contrast, other research groups found that DNA methylation and histone modification were in fact capable of regulating EpCAM gene expression (31). However, in HepG2 and K562 cell lines, following CpG island demethylation, EpCAM gene expression levels did not increase in either cell line. As it is widely known, DNA methylation and histone modification are interrelated epigenetic mechanisms known to play a key role in transcriptional control in some genes (32). One explanation was that EpCAM gene expression are related both to promoter demethylation and histone acetylation. On the other hand, EpCAM gene was a tissue-specific gene (4), and genes with tissue-specific expression can be divided in two groups according to the content of promoter $\mathrm{CpG}$ dinucleotides, and CpG-rich promoters depend solely on the presence of tissuespecific transcription factors (33). Furthermore, a significant difference of EpCAM expression in various subtype lung cancers was observed (34). Thus it is possible that EpCAM express may depend on the biological context of the tumor microenvironment and its expression in cancer could be tissue- and/or cell-specific.

In haematological tumor cell lines, the $\mathrm{CpG}$ island was completely methylated while in liver tumor cell lines, although EpCAM gene expressed the same level as the haematological tumor cell lines, only half of the $\mathrm{CpG}$ islands were methylated. This finding also implicated that the promoter demethylation was not responsible for EpCAM gene expression by itself.

In the SP1 site, the CpG dinucleotides were methylated, but the $\mathrm{CpG}$ dinucleotides around the AP1 site were 
unmethylated in all cell lines and tissues (Fig. 3). Ap1 site was nuclear transcription factor binding site (35), if it is possible that this nuclear transcription factor protects the AP1 site from methylation. Thus, still more research is necessary on this region.

In conclusion, the results of the study described herein suggest that unmethylation of the EpCAM promoter region was associated with EpCAM overexpression; however, it was later demonstrated that unmethylation was not responsible for EpCAM overexpression by itself. Clearly, further research is required to determine which factors are responsible for EpCAM gene expression.

\section{Acknowledgements}

This study was supported in part by DaAn Gene Co., Ltd of Sun Yat-sen University and National Ministry of Science and Technology of 863 Plan (NO:2006AA020902). The authors would like to sincerely thank Dr Wu Hongyang for providing the normal and colon cancer samples for this study.

\section{References}

1. Linnenbach AJ, Seng BA, Wu S, et al: Retroposition in a family of carcinoma-associated antigen genes. Mol Cell Biol 13: 1507-1515, 1993.

2. Litvinov SV, Velders MP, Bakker HA, Fleuren GJ and Warnaar SO: Ep-CAM: a human epithelial antigen is a homophilic cell-cell adhesion molecule. J Cell Biol 125: 437-446, 1994.

3. Litvinov SV, Bakker HA, Gourevitch MM, Velders MP and Warnaar SO: Evidence for a role of the epithelial glycoprotein 40 (Ep-CAM) in epithelial cell-cell adhesion. Cell Adhes Commun 2: 417-428, 1994.

4. Balzar M, Winter MJ, de Boer CJ and Litvinov SV: The biology of the 17-1A antigen (Ep-CAM). J Mol Med 77: 699-712, 1999.

5. Szala S, Froehlich M, Scollon M, et al: Molecular cloning of cDNA for the carcinoma-associated antigen GA733-2. Proc Natl Acad Sci USA 87: 3542-3546, 1990.

6. Simon B, Podolsky DK, Moldenhauer G, Isseibacher KJ Gattoni-Celli S and Brand SJ: Epithelial glycoprotein is a member of a family of epithelial cell surface antigens homologous to nidogen, a matrix adhesion protein. Proc Natl Acad Sci USA 87: 2755-2759, 1990.

7. Strnad J, Hamilton AE, Beavers LS, et al: Molecular cloning and characterization of a human adenocarcinoma/epithelial cell surface antigen complementary DNA. Cancer Res 49: 314-317, 1989.

8. Calabrese G, Crescenzi C, Morizio E, Palka G, Guerra E and Alberti S: Assignment of TACSTD1 (alias TROP1, M4S1) to human chromosome $2 \mathrm{p} 21$ and refinement of mapping of TACSTD2 (alias TROP2, M1S1) to human chromosome 1p32 by in situ hybridization. Cytogenet Cell Genet 92: 164-165, 2001.

9. Ragnhammar P, Fagerberg J, Frodin JE, et al: Effect of monoclonal antibody $17-1 \mathrm{~A}$ and GM-CSF in patients with advanced colorectal carcinoma - long-lasting, complete remissions can be induced. Int J Cancer 53: 751-758, 1993.

10. Riethmuller G, Holz E, Schlimok G, et al: Monoclonal antibody therapy for resected Dukes' C colorectal cancer: seven-year outcome of a multicenter randomized trial. J Clin Oncol 16: 1788-1794, 1998.

11. Went PT, Lugli A, Meier S, et al: Frequent EpCam protein expression in human carcinomas. Hum Pathol 35: 122-128, 2004.

12. Spizzo G, Obrist P, Ensinger C, et al: Prognostic significance of Ep-CAM AND Her-2/neu overexpression in invasive breast cancer. Int J Cancer 98: 883-888, 2002.
13. Seligson DB, Pantuck AJ, Liu X, et al: Epithelial cell adhesion molecule (KSA) expression: pathobiology and its role as an independent predictor of survival in renal cell carcinoma. Clin Cancer Res 10: 2659-2669, 2004.

14. Varga M, Obrist P, Schneeberger S, et al: Overexpression of epithelial cell adhesion molecule antigen in gallbladder carcinoma is an independent marker for poor survival. Clin Cancer Res 10: 3131-3136, 2004.

15. Gires O, Eskofier S, Lang S, Zeidler R and Munz M: Cloning and characterisation of a $1.1 \mathrm{~kb}$ fragment of the carcinomaassociated epithelial cell adhesion molecule promoter. Anticancer Res 23: 3255-3261, 2003

16. McLaughlin PM, Trzpis M, Kroesen BJ, et al: Use of the EGP2/Ep-CAM promoter for targeted expression of heterologous genes in carcinoma derived cell lines. Cancer Gene Ther 11: 603-612, 2004.

17. Jones PA and Baylin SB: The fundamental role of epigenetic events in cancer. Nat Rev Genet 3: 415-428, 2002.

18. Robertson KD: DNA methylation, methyltransferases, and cancer. Oncogene 20: 3139-3155, 2001.

19. Hanada M, Delia D, Aiello A, Stadtmauer E and Reed JC: bcl-2 gene hypomethylation and high-level expression in B-cell chronic lymphocytic leukemia. Blood 82: 1820-1828, 1993.

20. De Smet C, De Backer O, Faraoni I, et al: The activation of human gene MAGE-1 in tumor cells is correlated with genomewide demethylation. Proc Natl Acad Sci USA 93: 7149-7153, 1996.

21. Nakayama M, Wada M, Harada T, et al: Hypomethylation status of $\mathrm{CpG}$ sites at the promoter region and overexpression of the human MDR1 gene in acute myeloid leukemias. Blood 92: 4296-4307, 1998

22. Cho M, Uemura H, Kim SC, et al: Hypomethylation of the MN/CA9 promoter and upregulated MN/CA9 expression in human renal cell carcinoma. Br J Cancer 85: 563-567, 2001.

23. Rosty C, Ueki T, Argani P, et al: Overexpression of S100A4 in pancreatic ductal adenocarcinomas is associated with poor differentiation and DNA hypomethylation. Am J Pathol 160: 45-50, 2002.

24. Herman JG: Hypermethylation of tumor suppressor genes in cancer. Semin Cancer Biol 9: 359-367, 2002.

25. Bird A: DNA methylation patterns and epigenetic memory. Genes Dev 16: 6-21, 2002.

26. Herman JG and Baylin SB: Gene silencing in cancer in association with promoter hypermethylation. N Engl J Med 349: 2042-2054, 2003

27. Muller PY, Janovjak H, Miserez AR and Dobbie Z: Processing of gene expression data generated by quantitative real-time RT-PCR. Biotechniques 32: 1372-1379, 2002.

28. Brandeis M, Frank D, Keshet I, et al: Sp1 elements protect a $\mathrm{CpG}$ island from de novo methylation. Nature 371: 435-438, 1994.

29. Macleod D, Charlton J, Mullins J and Bird AP: Sp1 sites in the mouse aprt gene promoter are required to prevent methylation of the CpG island. Genes Dev 8: 2282-2292, 1994.

30. Spizzo G, Gastl G, Obrist P, et al: Methylation status of the Ep-CAM promoter region in human breast cancer cell lines and breast cancer tissue. Cancer Lett 246: 253-261, 2007.

31. Tai KY, Shiah SG, Shieh YS, et al: DNA methylation and histone modification regulate silencing of epithelial cell adhesion molecule for tumor invasion and progression. Oncogene 26: 3989-3997, 2007.

32. El-Osta A and Wolffe AP: DNA methylation and histone deacetylation in the control of gene expression: basic biochemistry to human development and disease. Gene Expr 9: 63-75, 2000.

33. Bird A: The essentials of DNA methylation. Cell 70: 5-8, 1992.

34. Went P, Vasei M, Bubendorf L, et al: (Frequent high-level expression of the immunotherapeutic target Ep-CAM in colon, stomach, prostate and lung cancers. Br J Cancer 94: 128-135, 2006.

35. Turner R and Tjian R: Leucine repeats and an adjacent DNA binding domain mediate the formation of functional cFos-cJun heterodimers. Science 243: 1689-1694, 1989. 